\title{
Validation of the Advanced Infra-Red Water Vapour Estimator (AIRWAVE) Total Column Water Vapour using Satellite and Radiosonde products
}

\author{
Enzo Papandrea ${ }^{1,2,}$, , Stefano Casadio ${ }^{1}$, ERminia De Grandis ${ }^{1}$, Elisa Castelli ${ }^{2}$, \\ BiANCA MARIA DiNELLI², BOJAN BOJKOV,, \\ ${ }^{1}$ SERCO s.p.a., Frascati, (RM), Italy \\ ${ }^{2}$ Istituto di Scienze dell' Atmosfera e del Clima, ISAC-CNR, Bologna, Italy \\ ${ }^{3}$ EUMETSAT, Darmstadt, Germany \\ Enzo.Papandrea@serco.com
}

\begin{abstract}
The Along Track Scanning Radiometer (ATSR) instrument series, on board the European Space Agency (ESA)'s European Remote Sensing (ERS) satellites, ERS-1/2 and the ENVIronmental SATellite (ENVISAT), covered the time period from 1991 to 2012. Using the infra-red channels at 11 and 12 microns (available for both day and night and for all the three instruments) and combining nadir and forward geometries, Total Column Water Vapour (TCWV) fields have been obtained over the sea in cloud free scenarios. The retrieval scheme, named Advanced InfraRed Water Vapor Estimator (AIRWAVE), exploits the instrument physical characteristics (dual view and two channels), in combination with advanced radiative transfer models and a sea surface spectral emissivity database. The algorithm makes use of a set of tabulated parameters, fixed along the whole globe.

Here, the AIRWAVE dataset is compared with the satellite data of the Special Sensor Microwave/Imager (SSM/I) and with available stations from the Analyzed RadioSoundings Archive (ARSA). Both comparisons demonstrated the good quality of the AIRWAVE dataset. However, they also highlighted the presence of a dry bias at high latitudes. Globally, we found an average correlativeAIRWAVE bias of $0.72 \mathrm{~kg} / \mathrm{m}^{2}\left(R M S E=5.79 \mathrm{~kg} / \mathrm{m}^{2}\right)$ vs SSM $/$ and $0.80 \mathrm{~kg} / \mathrm{m}^{2}\left(R M S E=7.77 \mathrm{~kg} / \mathrm{m}^{2}\right)$ vs ARSA.
\end{abstract}

\section{INTRODUCTION}

W ater vapour plays a crucial role both for the weather and the climate. It is indeed the most abundant greenhouse gas in the atmosphere (Kiehl and Trenberth, 1997). It is a strong absorber of infrared radiation and can amplify the effect of other greenhouse gases through positive feedback. Water vapour can condense to form clouds that greatly influence the heating rate and circulation of the atmosphere. In addition, it can influence the atmospheric composition through photochemical reactions.

Water vapour is highly variable in space and time. A good knowledge of its distribution is therefore essential for predicting the weather, monitoring the climate, and understanding the physics and chemistry of the atmosphere (Wang et al., 2016).

Observations of atmospheric water vapour abundance have been made using different instruments and platforms in order to study, e.g., its variability and trends. Among these we can list radio soundings (e.g., balloon-borne) and satellite missions, operating in different spectral regions (microwave (MW), near-infrared (NIR), UltraViolet-Visible (UV-VIS)). Water vapour distribution can also be derived using the Global Positioning System (GPS) technology. In addition to its observation, the scientific community has made an effort in intercomparing and validating 
the water vapour datasets obtained using different sensors.

The Along-Track Scanning Radiometer (ATSR, Delderfield et al., 1986) instrument series had as main objective the accurate retrieval of sea surface temperature for climate studies. However, Casadio et al. (2016) demonstrated that it is possible to retrieve accurate Total Column Water Vapour (TCWV) fields, in both daytime and night-time conditions, combining the ATSR Brightness Temperature collected from nadir and forward views in the channels at 10.8 and $12 \mu \mathrm{m}$ for cloud-free sea scenes. The new AIRWAVE (Advanced Infra-Red Water Vapour Estimator) algorithm has been applied to the whole ATSR mission to develop a new TCWV database. Here we describe the validation of the AIRWAVE TCWV dataset against both the satellite-based (i.e. the Special Sensor Microwave/Imager, $\mathrm{SSM} / \mathrm{I}$ ) and in situ radiosonde measurements (the Analyzed RadioSoundings Archive, ARSA).

\section{DATASETS DESCRIPTION}

\section{The Advanced InfraRed Water Vapor Estimator (AIRWAVE)}

The AIRWAVE algorithm was used to retrieve TCWV for the three ATSR missions in the 19912012 time range. Roughly, 21000 orbits for ATSR1, 35500 orbits for ATSR-2 and 48000 orbits for AATSR have been processed on the Grid Processing on Demand (G-POD) ESA infrastructure.

Information on the AIRWAVE/G-POD processor can be found here: http:/ / wiki.services.eoportal.org $/$ tiki-index.php? page=G-POD+services . The retrieval code is computationally very efficient as it makes use of tabulated parameters obtained with a dedicated Radiative Transfer Model (RTM). A detailed description of the algorithm can be found in Casadio et al. (2016). The native spatial resolution of the AIRWAVE products is $1 \times 1 \mathrm{~km}^{2}$, however they have been also regridded at lower resolution $\left(0.25^{\circ} \times 0.25^{\circ}\right.$, approximately $28 \times 28 \mathrm{~km}^{2}$ ). According to Casadio et al. (2016), the AIRWAVE random error component at native resolution is estimated to be about $12 \%$ for ATSR-2 and AATSR, while it is about $30 \%$ for ATSR-1. The AIRWAVE algorithm requires that the observed scene is a cloud free water surface. Indeed, clouds affect the atmospheric radiation both because of their relatively high reflectance and because they partly shield the atmosphere below them, causing i.e. inaccurate gas abundance retrieval (see e.g., Raspollini et al., 2006). The current limit of AIRWAVE to water scenes can be in principle overcome with the availability of an extremely accurate auxiliary information on land emissivity (Casadio et al., 2016). The ATSR Level $1 \mathrm{~b}$ products contain auxiliary information on the observed surface (land/sea) and on cloud coverage (cloud mask) for both nadir and forward views. Therefore only a subset of available Level $1 \mathrm{~b}$ measurements was processed, selecting only the pixels above water and filtering out the pixels flagged as cloudy in either the nadir or in the forward view. The ATSR cloud mask is the result of a series of nine independent tests using different threshold values applied to individual Short Wavelength Infrared (SWIR), Mid Infrared (MIR) or Thermal Infrared (TIR) channels or to a combination of channels (Závody et al., 2000; ESA, 2007).

Monthly fields of the AIRWAVE TCWV products at $2^{\circ} \times 2^{\circ}$ spatial resolution, spanning from 2003 to 2008, are freely available on the Global Energy and Water Exchanges (GEWEX) Water Vapor Assessment (G-VAP) website (http://gewexvap.org/).

\section{The Special Sensor Microwave/Imager (SSM/I)} The SSM/I series of instruments are near-polar orbiting satellites, with the Defense Meteorological Satellite Program (DMSP)-F08 being the first one launched in 1987. The imager operates at the following four frequencies: 19.35, 22.235, 37, and 85.5 GHz. Exploiting the brightness temperature measured over the oceans in these channels, it is possible to retrieve important geophysical pa- 
rameters over the ocean, such as near-surface wind speed, columnar water vapour, and columnar cloud liquid water (Wentz, 1997). The author estimated, for SSM/I water vapour products, a systematic error of $0.6 \mathrm{~kg} / \mathrm{m}^{2}$ and a root mean square retrieval accuracy of $1.2 \mathrm{~kg} / \mathrm{m}^{2}$.

The SSM/I TCWV dataset was produced by Remote Sensing Systems (Wentz et al., 2012). Among the available products, daily mean at spatial grid resolution $0.25^{\circ} \times 0.25^{\circ}$ have been used for this analysis. The V7 water vapour products of the DMSP-F13 satellite, used in this analysis, have been compared with GPS in Hilburn et al. (2010), founding a mean SSM/IGPS bias of $-0.1 \mathrm{~kg} / \mathrm{m}^{2}$ and a standard deviation of $1.83 \mathrm{~kg} / \mathrm{m}^{2}$.

\section{The Analyzed RadioSoundings Archive (ARSA)}

The ARSA database was produced by the Laboratoire de Météorologie Dynamique (LMD) to fulfil the needs of different applications, e.g., for the validation of forward and inverse models or satellite measurements (http: / / ara.abct.lmd.polytechnique.fr / index.php?page=arsa).

The ARSA database was started in January 1979, and has been extended onwards, on a monthly basis. The data inserted in the archive have passed different quality control tests in order to be free of gross errors: format problems, redundant radiosoundings and levels, unrealistic jumps, physically implausible values, temporal and vertical inconsistencies in temperature and dew point temperatures.

The dataset contains water vapour abundances reported at specific pressure levels (nominally 43 levels between sea level pressure and 0.0025 $\mathrm{hPa}$ ). In ARSA the coverage of the full vertical atmospheric range is assured: in case of partial missing information, indeed, other reliable data sources or an extrapolation procedure up to the lower pressure level of the atmosphere are used. An estimate of radiosounding mixing ratio uncertainty of $2 / 3 \%$ was obtained by Vömel et al.
(2016). They also found a bias of 3\% in the lower troposphere, in about $15 \%$ of all instruments. However, they concluded that the impact on studies using a large number of soundings such as satellite comparisons is considered small.

\section{METHODS}

For the comparison of AIRWAVE-TCWV with SSM/I data we used the F13 satellite products, because they cover a long time period (19952009) that overlaps with the measurements of all three ATSR instruments. Furthermore, the local time of the ascending node of the F13 satellite (about 18:00) is more stable in comparison to other available SSM/I satellites. In fact, it varies less than one hour from the start to the end of the mission (more details can be found at http: / / www.remss.com/ support/ crossingtimes). This stability over time makes the comparison free from seasonal bias and minimise potential year to year differences.

The spatial grid used for the comparison coincides with the SSM/I resolution $\left(0.25^{\circ} \times 0.25^{\circ}\right)$, thus the AIRWAVE TCWVs have been aggregated to this grid. In the aggregation process, the amount of available AIRWAVE products in any grid cell ("pixel coverage" or COV) is also stored. Therefore only SSM/I products in coincidence with valid AIRWAVE measurements, i.e. $\mathrm{COV}>2 \%$ were used for the comparison, in order to reduce potential biases due to SSM/I TCWV retrieved in presence of clouds. In fact most of AIRWAVE missing data are due to cloud coverage of the observed scene.

For the comparison with ARSA we found, globally, about 1400 stations having data in the time period coincident with the ATSR missions. Out of them, only sites surrounded, even partially, by water surfaces have been selected since AIRWAVE data are available only above water surfaces. For each sounding station, the proximity to water surfaces has been estimated using the high-quality $\left(0.083^{\circ} \times 0.083^{\circ}\right)$ land-sea mask 
"lsmask-world8-ar.dist5.5.nc" from Group for High-Resolution Sea Surface Temperature (https://www.ghrsst.org/) by computing the percentage of sea surface values in a radius of $100 \mathrm{~km}$ centred on the station's location. The final number of ARSA stations selected for this analysis is 615. For every selected station we averaged the AIRWAVE products (at their native resolution) collocated with the radiosonde measurements. The collocation criteria are: 1) separate matching for day and night; 2) AIRWAVE measurements must be located within the radius of $100 \mathrm{~km}$ around the position of the station. The ARSA TCWV is obtained by integrating the humidity profile over the full pressure range.

\section{RESULTS AND DISCUSSION}

Bi-dimensional histograms of the comparison between the TCWV retrieved with AIRWAVE and SSM/I (upper panel) and ARSA (lower panel) are shown in Figure 1 using a bin size of $2.5 \mathrm{~kg} / \mathrm{m}^{2}$. The selected ARSA measurements mainly come from mid-latitude regions located in the northern hemisphere (see Figure 3) and, as a consequence, are more representative of TCWV ranging from 3 to $30 \mathrm{~kg} / \mathrm{m}^{2}$ while SSM/I measurements, being more homogeneously distributed all over the globe, extend the range up to $50 \mathrm{~kg} / \mathrm{m}^{2}$.

Globally, a good correlation is found for TCWV values larger than $7.5 \mathrm{~kg} / \mathrm{m}^{2}$ both against satellite and balloon-borne measurements, while below this value AIRWAVE performances deteriorate. This is because the channels used by AIRWAVE are less sensitive to dry atmospheric conditions, causing, as can be seen in Figure 1, non-physical negative TCWV values.

Figure 2 reports AIRWAVE TCWV zonal means as a function of latitude in bins of 2 degrees (blue dots) and their standard deviations (blue vertical lines). The correlative measurements SSM/I (left) or ARSA (right), binned as AIRWAVE data are showed in black. The two panels
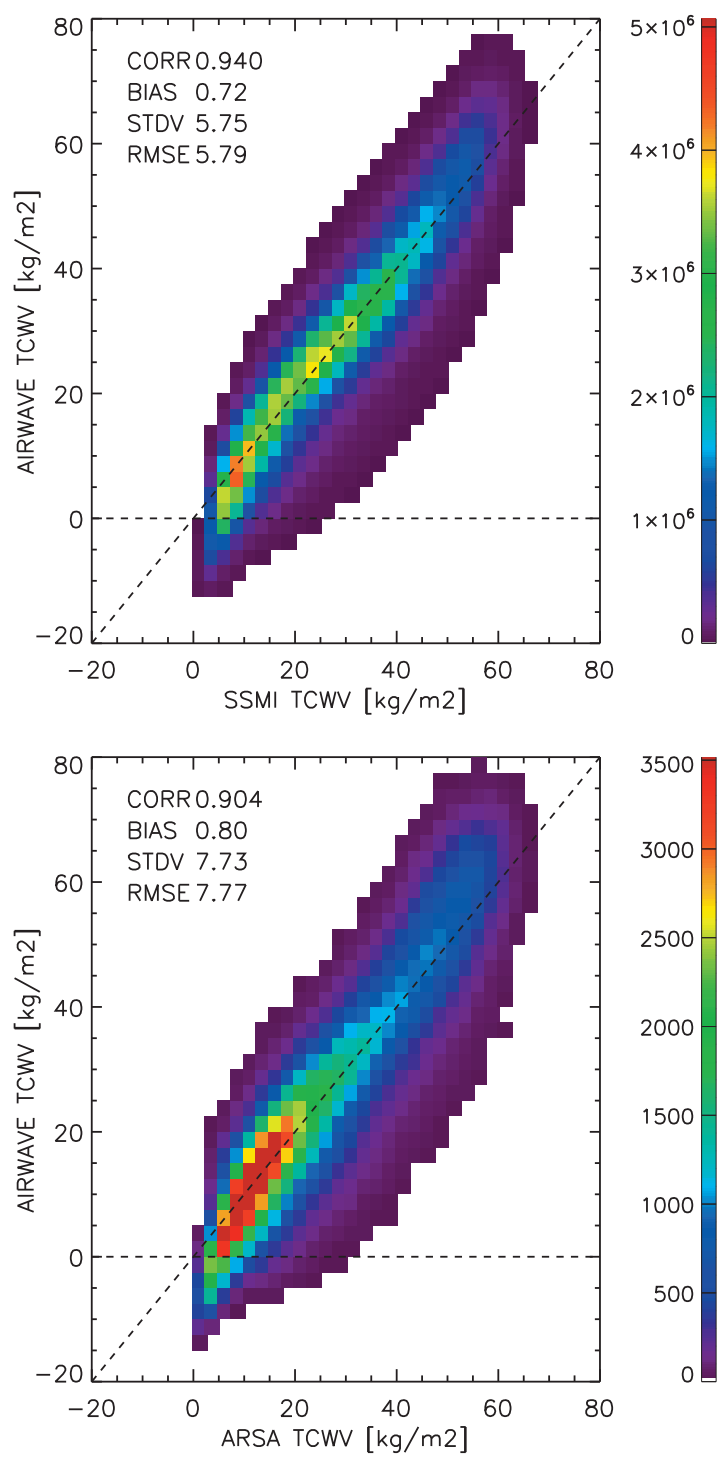

3500
3000
2500
2000
1500
1000
500
0

Figure 1: AIRWAVE TCWV vs SSM/I TCWV (up) or ARSA TCWV (down). The bin size is $2.5 \mathrm{~kg} / \mathrm{m}^{2}$. The colour scale indicates the number of elements of the histogram.

highlight the good quality of AIRWAVE TCWV in the equatorial and mid-latitude bands (up to 45/50 latitude degrees). Indeed, as already mentioned, AIRWAVE retrievals are less reliable for low TCWV, typical condition at high latitudes. Moreover, as highlighted in Casadio et al. (2016), AIRWAVE uses a single set of parameters over the whole globe, computed as the weighted average of mid-latitude and tropical atmospheric conditions and therefore worse 

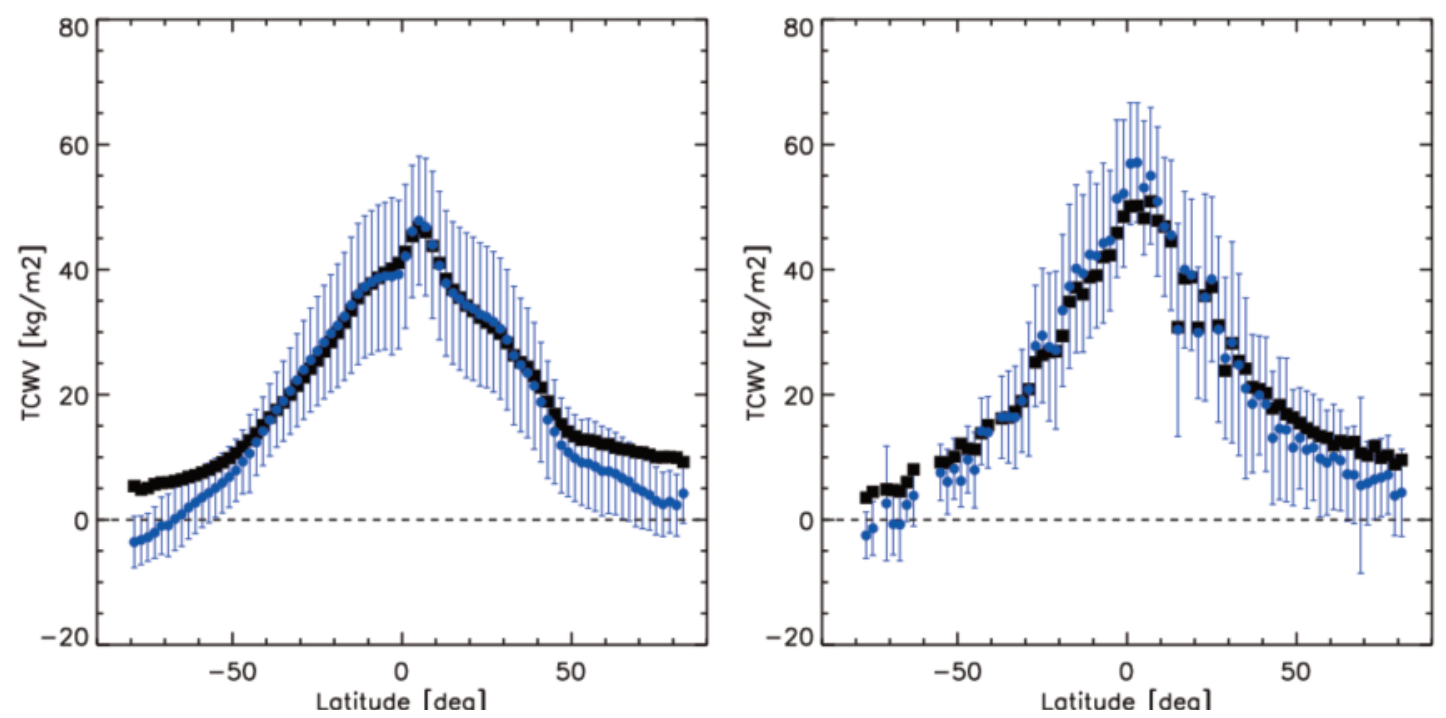

Figure 2: Zonal means of TCWV as a function of latitude for AIRWAVE (blue) and correlative measurements (black): SSM/I (left) or ARSA (right). The data have been averaged in 2 degrees latitude bins. AIRWAVE TCWVs standard deviations are also reported.

performances were expected for the other latitude bands.

Figure 3 shows the geographical distribution of

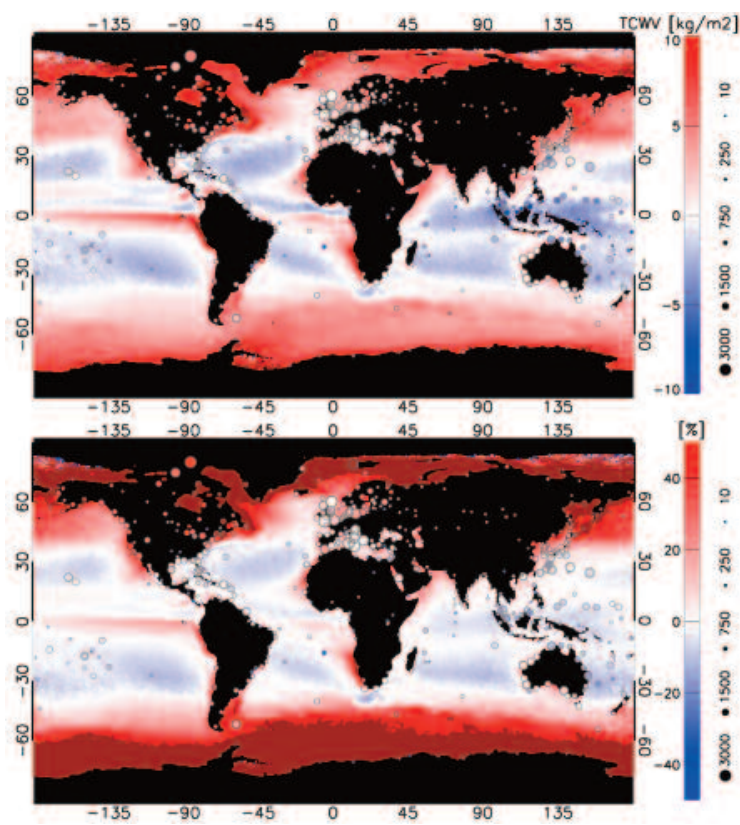

Figure 3: Average absolute (top) and relative (bottom) TCWV difference (SSM/I-AIRWAVE) at $0.25^{\circ} \times 0.25^{\circ}$ spatial resolution. Average ARSA-AIRWAVE TCWV differences are overplotted with circles; the size of the symbols is proportional to the number of matches (see legend). the mean TCWV differences (top panel=absolute, bottom panel=relative) using, as correlative dataset, SSM/I and ARSA (overplotted circles). The size of the symbol used for the latter is related to the number of matches with each radiosonde. Once again, small bias values are found in the regions between 50S/50N latitude degrees. A small longitudinal structure is observed. This is probably caused by the cloud coverage distribution that has a different impact on different areas. Indeed, considering the difference in the acquisition time of the two instruments and the fact that SSM/I measures in all weather conditions, the same scene, cloud-free on ATSRs observations, may be cloudy when acquired by SSM/I. To be noticed that AIRWAVE TCWV appears to be often lower than correlative measurements in proximity of the coastal areas. In the southern hemisphere, close to the Equator, a positive bias is found over the central and east Pacific and over the Atlantic oceans.

Figure 4 shows monthly mean trends of the TCWVs difference (and their standard deviation), between the correlative measurements (SSM/I in azure or ARSA in blue) and AIRWAVE. The monthly average negative bias, present at 


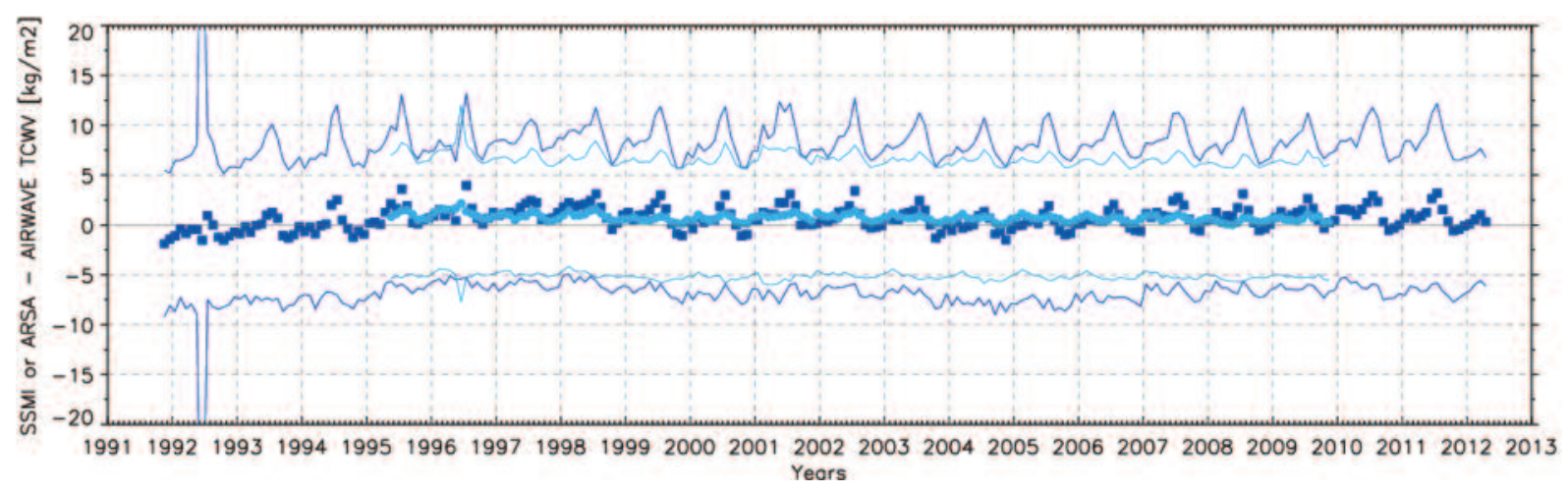

Figure 4: SSM/I-AIRWAVE TCWV (azure) and ARSA-AIRWAVE TCWV (blue) monthly mean trends. The difference between the correlative measurements and AIRWAVE TCWV $\pm S T D V$ is also reported.

the beginning of the ATSR- 1 mission, is progressively reduced and, since 1995, the difference between AIRWAVE and the collocated measurements is quite stable over time. The reason of the behaviour in the early part of the ATSR-1 mission is a downlink problem causing very little $1.6 \mu \mathrm{m}$ data available prior to the failure of the $3.7 \mu \mathrm{m}$ channel in May 1992. This, in turn, impacts the daytime cloud screening, which relies on the 1.6 $\mu \mathrm{m}$ channel (Corlett, 2016). Very consistent findings are reported both with satellite and radiosonde matches, with a higher seasonality observed for the selected radiosondes, that are located in coastal or inner water regions characterized by a pronounced variability of atmospheric and surface conditions. Table 1 sum-

\begin{tabular}{|c|c|c|c|c|c|c|c|c|c|}
\hline \multirow[b]{2}{*}{ Instrument } & \multirow[b]{2}{*}{ Scenario } & \multicolumn{4}{|c|}{ SSM/I-AIRWAVE } & \multicolumn{4}{|c|}{ ARSA-AIRWAVE } \\
\hline & & $\mathrm{N} \cdot 10^{5}$ & BIAS & $\begin{array}{l}\text { STDV } \\
/ \mathrm{m}^{2} \text { or }(\end{array}$ & RMSE & $\mathrm{N} \cdot 10^{5}$ & BIAS & $\begin{array}{l}\text { STDV } \\
/ \mathrm{m}^{2} \text { or }\end{array}$ & RMSE \\
\hline All & Global & 3110 & $\begin{array}{l}0.72 \\
(2.7)\end{array}$ & $\begin{array}{l}5.75 \\
(21)\end{array}$ & $\begin{array}{l}5.79 \\
(22)\end{array}$ & 3.01 & $\begin{array}{l}0.80 \\
(3.2)\end{array}$ & $\begin{array}{l}7.73 \\
(31)\end{array}$ & $\begin{array}{l}7.77 \\
(31)\end{array}$ \\
\hline All & Equatorial & 1560 & $\begin{array}{l}-0.17 \\
(-0.5)\end{array}$ & $\begin{array}{l}5.57 \\
(15)\end{array}$ & $\begin{array}{l}5.57 \\
(15)\end{array}$ & 0.87 & $\begin{array}{l}-2.40 \\
(-6.0)\end{array}$ & $\begin{array}{l}7.74 \\
(19)\end{array}$ & $\begin{array}{l}8.10 \\
(20)\end{array}$ \\
\hline All & Midlat & 1380 & $\begin{array}{l}1.12 \\
(6.1)\end{array}$ & $\begin{array}{l}5.89 \\
(32)\end{array}$ & $\begin{array}{l}5.99 \\
(33)\end{array}$ & 1.80 & $\begin{array}{l}1.69 \\
(8.4)\end{array}$ & $\begin{array}{l}7.44 \\
(37)\end{array}$ & $\begin{array}{l}7.63 \\
(38)\end{array}$ \\
\hline All & Polar & 170 & $\begin{array}{l}5.55 \\
(62)\end{array}$ & $\begin{array}{l}5.14 \\
(57)\end{array}$ & $\begin{array}{l}7.57 \\
(84)\end{array}$ & 0.35 & $\begin{array}{l}4.12 \\
(39)\end{array}$ & $\begin{array}{l}6.47 \\
(61)\end{array}$ & $\begin{array}{l}7.67 \\
(72)\end{array}$ \\
\hline ATSR-1 & Global & 190 & $\begin{array}{l}1.15 \\
(4.3)\end{array}$ & $\begin{array}{l}6.17 \\
(23)\end{array}$ & $\begin{array}{l}6.28 \\
(24)\end{array}$ & 0.48 & $\begin{array}{l}0.23 \\
(1.0)\end{array}$ & $\begin{array}{c}7.62 \\
(33 \%)\end{array}$ & $\begin{array}{c}7.63 \\
(33 \%)\end{array}$ \\
\hline ATSR-2 & Global & 1390 & $\begin{array}{l}0.80 \\
(3.0)\end{array}$ & $\begin{array}{l}5.87 \\
(22)\end{array}$ & $\begin{array}{l}5.92 \\
(22)\end{array}$ & 1.00 & $\begin{array}{l}1.13 \\
(4.7)\end{array}$ & $\begin{array}{l}7.65 \\
(32)\end{array}$ & $\begin{array}{l}7.73 \\
(32)\end{array}$ \\
\hline AATSR & Global & 1520 & $\begin{array}{l}0.58 \\
(2.1)\end{array}$ & $\begin{array}{l}5.77 \\
(21)\end{array}$ & $\begin{array}{l}5.80 \\
(21)\end{array}$ & 1.53 & $\begin{array}{l}0.75 \\
(2.9)\end{array}$ & $\begin{array}{l}7.81 \\
(31)\end{array}$ & $\begin{array}{l}7.84 \\
(31)\end{array}$ \\
\hline
\end{tabular}

Table 1: AIRWAVE TCWVs compared with SSM/I and ARSA stations. Absolute and relative differences along with the standard deviations and root mean square errors are reported for the global (all latitudes), equatorial (25S-25N), mid-latitude (25S$60 S$ and $25 \mathrm{~N}-60 \mathrm{~N}$ ) and polar ( $>60 \mathrm{~N}$ or $>60 S$ ) scenarios. Average values for the ATSR-1, ATSR-2 and AATSR are also provided. 
marises the results of the validation exercise. It reports absolute and relative differences (bias = correlative - AIRWAVE TCWV), standard deviations and root mean square errors for the global, equatorial, mid-latitude and polar scenarios. The number of collocations for SSM/I is about three orders of magnitude larger than for ARSA. SSM/I comparisons show that in the equatorial band the agreement is very good, with average bias of $-0.17 \mathrm{~kg} / \mathrm{m}^{2}$ while a larger difference $(-2.40$ $\mathrm{kg} / \mathrm{m}^{2}$ ) is found vs ARSA.

The more pronounced negative bias of the comparison with the radiosondes can be explained by the fact that they are located mostly around the Southeast Asia where a wet bias is present also in the comparison with SSM/I. At mid-latitudes, similar results are found both against $\mathrm{SSM} / \mathrm{I}\left(1.12 \mathrm{~kg} / \mathrm{m}^{2}\right)$ and ARSA $\left(1.69 \mathrm{~kg} / \mathrm{m}^{2}\right)$. Larger biases are present in the polar areas (5.55 $\mathrm{kg} / \mathrm{m}^{2} \mathrm{vs} \mathrm{SSM} / \mathrm{I}$ and $4.12 \mathrm{~kg} / \mathrm{m}^{2}$ vs ARSA).

The analysis performed separately for the three ATSR instruments does not show instrument related features, a part for the early stage of ATSR1 measurements. ATSR-1 data versus radiosondes, globally, show a lower bias with respect to the other two instruments. This is not observed with SSM/I, as F13 measurements start in 1995 and, thus, do not cover the initial part of ATSR-1 mission (see Figure 4).

\section{CONCLUSIONS}

In this work we show the results of an extensive validation of the AIRWAVE TCWV dataset. We obtain similar conclusions using both satellite and balloon-borne products. We find an overall bias of about 3\% partially due to TCWV retrieved in polar and coastal regions. When analysing the whole dataset we find no evident drift in the biases and correlated standard deviations thus highlighting the stability of the AIRWAVE TCWV and its very good accuracy. A potential improvement of the dataset should aim at solving the problem of negative values and at the reduction of the bias (and spread), especially in polar areas. Acknowledgements

This work has been performed under the ESAESRIN Contract No. 4000108531/13/I-NB and Contract No: 4000111304/14/I-AM. We thank the $\mathrm{ARA} / \mathrm{ABC}(\mathrm{t}) / \mathrm{LMD}$ group for producing and making available the Analyzed RadioSounding Archive (ARSA) database. SSM/I and SSM/IS data are produced by Remote Sensing Systems. Data are available at www.remss.com/missions/ssmi .

\section{REFERENCES}

Casadio, S., Castelli, E., Papandrea, E., Dinelli, B., Pisacane, G., Burini, A., and Bojkov, B. (2016). Total column water vapour from along track scanning radiometer series using thermal infrared dual view ocean cloud free measurements: The advanced infra-red water vapour estimator (AIRWAVE) algorithm, Remote Sensing of Environment, 172, 1-14.

Corlett, G.K. (2016). (A)ATSR Validation Activities/Validation Issues Report Ref: ULAATSR-VIR Issue: 5D.

Delderfield, J., Llewellyn-Jones, D.T., Bernard, R., de Javel, Y., Williamson, E.J., Mason, I., Pick, D.R. and Barton, I.J. (1986). The Along Track Scanning Radiometer (ATSR) for ERS-1. Proc. SPIE 589, 114-120.

ESA, H. A. P. (2007). Issue 2.2, European Space Agency, available at: http://envisat. esa. int/handbooks/aatsr/ (last access: 19 July 2017), 4056, 5.

Hilburn K.A., Wentz F.J., Mears C.A., Meissner T., Smith D. K., Description of Remote Sensing Systems Version-7 Geophysical Retrievals (2010). Remote Sensing Systems, available at: http://www.ssmi.com/papers/hilburn/Hilburn_V7_Poster_AMS_Sat Met_2010_Annapolis.pdf.

Kiehl, J. T. and Trenberth, K. E. (1997). Earth's annual global mean energy budget, Bulletin of the American Meteorological Society, 78, 197-208.

Raspollini, P., Belotti, C., Burgess, A., Carli, B., 
Carlotti, M., Ceccherini, S., Dinelli, B. M., Dudhia, A., Flaud, J.-M., Funke, B., Höpfner, M., López-Puertas, M., Payne, V., Piccolo, C., Remedios, J. J., Ridolfi, M., and Spang, R. (2006). MIPAS level 2 operational analysis, Atmos. Chem. Phys., 6, 5605-5630, https: / / doi.org/10.5194/ acp-6-5605-2006.

Vömel Holger, Tatjana Naebert, Ruud Dirksen, and Michael Sommer (2016). An update on the uncertainties of water vapor measurements using cryogenic frost point hygrometers, Atmos. Meas. Tech., 9, 3755-3768.

Wang, H., Gonzalez Abad, G., Liu, X., and Chance, K. (2016). Validation and update of OMI Total Column Water Vapor product, Atmospheric Chemistry and Physics, 16, 11 37911393.

Wentz, F. J. (1997). A well-calibrated ocean algorithm for SSM/I. Journal of Geophysical Research, 102(C4), 8703-8718.

Wentz, F. J., Hilburn, K.A., and Smith, D. K.: Remote Sensing Systems DMSP SSM/I Daily Environmental Suite on 0.25 deg grid, Version 7 (2012). Remote Sensing Systems, Santa Rosa, CA. Available online at www.remss.com/missions/ssmi/ (last access: 19 July 2017).

Závody, A. M., Mutlow, C. T., and LlewellynJones, D. T. (2000). Cloud clearing over the ocean in the processing of data from the Along-Track Scanning Radiometer (ATSR), Journal of Atmospheric and Oceanic Technology, 17, 595-615.

\footnotetext{
* A thank you or further information. Enzo Papandrea SERCO s.p.a., Frascati, (RM), Italy; ISAC-CNR, Bologna, Italy.

paps101@gmail.com
} 